\title{
BMJ Open Aetiology and risks factors associated with the fatal outcomes of childhood pneumonia among hospitalised children in the Philippines from 2008 to 2016: a case series study
}

Bindongo Price Polycarpe Dembele, ${ }^{1}$ Taro Kamigaki, ${ }^{1}$ Clyde Dapat, ${ }^{1}$ Raita Tamaki, ${ }^{1}$ Mariko Saito, ${ }^{1}$ Mayuko Saito, ${ }^{1}$ Michiko Okamoto, ${ }^{1}$ Mary Ann U Igoy, ${ }^{2}$ Edelwisa Segubre Mercado, ${ }^{2}$ Melisa Mondoy, ${ }^{2}$ Veronica L Tallo, ${ }^{2}$ Socorro P Lupisan, ${ }^{2}$ Shinichi Egawa, ${ }^{3}$ Hitoshi Oshitani ${ }^{1}$

To cite: Dembele BPP Kamigaki T, Dapat C, et al. Aetiology and risks factors associated with the fatal outcomes of childhood pneumonia among hospitalised children in the Philippines from 2008 to 2016: a case series study. BMJ Open 2019;9:e026895. doi:10.1136/ bmjopen-2018-026895

- Prepublication history and additional material for this paper are available online. To view these files, please visit the journal online (http://dx.doi. org/10.1136/bmjopen-2018026895).

Received 25 September 2018 Revised 28 February 2019 Accepted 1 March 2019
Check for updates

(c) Author(s) (or their employer(s)) 2019. Re-use permitted under CC BY-NC. No commercial re-use. See rights and permissions. Published by BMJ.

For numbered affiliations see end of article.

Correspondence to

Hitoshi Oshitani;

oshitanih@med.tohoku.ac.jp

\section{ABSTRACT}

Objective Pneumonia remains the leading cause of hospitalisations and deaths among children aged $<5$ years. Diverse respiratory pathogens cause acute respiratory infections, including pneumonia. Here, we analysed viral and bacterial pathogens and risk factors associated with death of hospitalised children.

Design A 9-year case series study.

Setting Two secondary-care hospitals, one tertiary-care hospital and one research centre in the Philippines.

Participants 5054 children aged $<5$ years hospitalised with severe pneumonia.

Methods Nasopharyngeal swabs for virus identification, and venous blood samples for bacterial culture were collected. Demographic, clinical data and laboratory findings were collected at admission time. Logistic regression analyses were performed to identify the factors associated with death.

Results Of the enrolled patients, $57 \%$ (2876/5054) were males. The case fatality rate was $4.7 \%(238 / 5054)$, showing a decreasing trend during the study period $(p<0.001) .55 .0 \%$ of the patients who died were either moderately or severely underweight. Viruses were detected in $61.0 \%$ of the patients, with respiratory syncytial virus $(27.0 \%)$ and rhinovirus $(23.0 \%)$ being the most commonly detected viruses. In children aged 2-59 months, the risk factors significantly associated with death included age of 2-5 months, sensorial changes, severe malnutrition, grunting, central cyanosis, decreased breath sounds, tachypnoea, fever $\left(\geq 38.5^{\circ} \mathrm{C}\right)$, saturation of peripheral oxygen $<90 \%$, infiltration, consolidation and pleural effusion on chest radiograph. Among the pathogens, adenovirus type 7, seasonal influenza $A$ (H1N1) and positive blood culture for bacteria were significantly associated with death. Similar patterns were observed between the death cases and the aforementioned factors in children aged $<2$ months.

Conclusion Malnutrition was the most common factor associated with death and addressing this issue may decrease the case fatality rate. In addition, chest radiographic examination and oxygen saturation

\section{Strengths and limitations of this study}

- A large sample size of more than 5000 patients studied over a longer duration of 9 years in a lower-middle-income country.

- The study tested almost $100 \%$ of nasopharyngeal samples collected from patients for 13 different viruses.

Dxygen saturation measurement using pulse oximetry was obtained from $99 \%$ of all patients enrolled in the study.

- Chest radiographs were available and interpretable from $4452(88 \%)$ patients.

- Limited findings for bacterial culture identification due to lower sampling rate for blood culture among fatal cases.

measurement should be promoted in all hospitalised patients with pneumonia as well as bacteria detection to identify patients who are at risk of death.

\section{BACKGROUND}

Pneumonia is the most important cause of childhood mortality in children aged $<5$ years. It is estimated to cause 896000 deaths of the total 5.6 million deaths in 2016 alone. ${ }^{1}$ Most of these deaths occurred in low-income and middle-income countries (LMIC). ${ }^{2}$ Integrated Management of Childhood Illness (IMCI), which was developed by the WHO and UNICEF, has been widely used for the better management of common childhood illnesses, including pneumonia in LMIC. Bacteria are considered to be an important aetiology of childhood pneumonia, and the detection of bacterial pathogens has been associated with deaths. ${ }^{34}$ Vaccination programmes for 
bacterial pathogens ${ }^{56}$ have also been introduced to reduce the negative impact of childhood pneumonia in several LMIC, including vaccines against Haemophilus influenzae type b and Streptococcus pneumoniae. ${ }^{78}$ These vaccines have contributed to the reduction of morality from childhood pneumonia. ${ }^{1}{ }^{10}$ Viruses are commonly identified from children with acute lower respiratory infection (ALRI), including pneumonia. At least 26 viruses are known to cause childhood pneumonia, ${ }^{11}$ and respiratory syncytial virus (RSV) is one of these common viruses detected from children with ALRI. The most recent estimates on the global burden of RSV indicate that 33.1 million episodes of RSV-associated ALRI with 59600 in-hospital deaths among children of age $<5$ years in $2015 .{ }^{12}$ Influenza virus (IFV) infection has also been shown to have a significant impact on children worldwide, with an estimated 28 000-111500 deaths in children aged $<5$ years. ${ }^{13}$ Other common viruses identified from ALRI include rhinovirus (RV), human metapneumovirus (HMPV), parainfluenza virus (PIV) and adenovirus (ADV). ${ }^{14-16}$ More recently, enterovirus D68 (EV-D68) was found to be associated with ALRI. ${ }^{17}$ However, the impact of these viral infections on childhood pneumonia mortality remains to be adequately characterised.

Some risk factors and clinical signs, including nutritional status, ${ }^{2} 1819$ low birth weight, ${ }^{20}$ hypoxia, cyanosis and grunting, ${ }^{21}{ }^{22}$ and radiological findings, ${ }^{23}$ are well described as the predictors of death in childhood pneumonia. Nonetheless, further reduction of mortality due to childhood pneumonia requires a better understanding of the association between death and viral infections and requires an update of all factors associated with death in general. The present study aimed to define the aetiological, demographic and environmental factors and clinical findings associated with mortality due to childhood pneumonia among hospitalised children in the Philippines.

\section{METHODS}

\section{Study sites}

The present study was conducted across four hospitals in the Philippines which include the Biliran Provincial Hospital (BPH), Eastern Visayas Regional Medical Center (EVRMC), Ospital ng Palawan (ONP) and Research Institute for Tropical Medicine (RITM). BPH is the only hospital in Biliran Island with 50 paediatric beds and four emergency rooms. EVRMC is a tertiary-care government hospital for the Eastern Visayas Region with a 250-bed capacity including 50 paediatric beds. ONP is a secondary referral government hospital in Palawan Island with 40 beds in the paediatric department and 10 beds in the intensive care unit. RITM is a specialised tertiary-care hospital in Metro Manila with 50 beds. In the Philippines, tertiary hospitals are referral facilities for patients needing tertiary care, such as intensive and emergency care, mechanical ventilation and major surgeries. Secondary hospitals are for patients who need hospitalisation for simple cases, such as fever, diarrhoea and pneumonia not requiring emergency care. The study periods varied among the hospitals, with that for $\mathrm{BPH}$ from September 2012 to March 2016, for EVRMC from June 2008 to January 2015, for ONP from August 2012 to February 2015 and for RITM from September 2012 to January 2015.

\section{Study design}

This was a case series study of hospitalised children with pneumonia in the Philippines evaluating associated risk factors for fatal outcome.

\section{Study patients}

Children aged 8 days to $<5$ years who were hospitalised in the above mentioned medical facilities with acute respiratory symptoms were assessed using the IMCI algorithm by trained study physicians. ${ }^{6}$ Patients who were assessed to have severe pneumonia or very severe pneumonia by the IMCI algorithm were enrolled in the study. In 2014, the IMCI algorithm for acute respiratory infection was revised, ${ }^{24}$ and children with chest indrawing are no longer diagnosed as severe pneumonia cases and are not required to be hospitalised. However, this new algorithm was not widely implemented in the Philippines during the study period, and we continued to recruit patients with chest indrawing and those with danger signs based on the previous IMCI algorithm. Exclusion criteria included children aged less than 8 days old or 5 years or more, children admitted for another illness and who had developed symptoms of pneumonia during hospitalisation, children who had been admitted to another hospital within the last 3 days prior to the present admission and children who had prior hospital admission without 1-week symptom-free period when readmitted to the hospital.

Patient outcomes were grouped into two categories: survived and died. The survived group comprised patients who were discharged, including those discharged against medical advice (DAMA) but with improved conditions. The died group comprised patients with pneumonia who died during the hospitalisation period or were DAMA with a deteriorated condition at their last clinical assessment. We assumed that all DAMA patients with a deteriorated condition were likely to die based on a previous study in the Philippines. ${ }^{3}$

Congenital abnormalities included congenital heart disease, trisomy 21 syndrome, cerebral palsy or other neurodevelopmental conditions and inherited haemolytic anaemia. Tachypnoea was defined as follows: respiratory rate $(\mathrm{RR}) \geq 60$ breaths $/ \mathrm{min}$ in children $<2$ months, $\mathrm{RR} \geq 50$ breaths per min in children aged 2-11 months and $R R \geq 40$ breaths $/$ min in children aged $\geq 12$ months. Tachycardia was defined as heart rate $\geq 180$ beats $/ \mathrm{min}$ (bpm) for children aged $<12$ months and $\geq 140 \mathrm{bpm}$ for children aged $\geq 12$ months. The WHO child growth standards were used to evaluate the nutritional status of children by computing the Z-scores of weight-for-age and height-for-age.$^{25}$ Saturation of peripheral oxygen $\left(\mathrm{SpO}_{2}\right)$ was measured on admission by using a pulse oximeter 
(Handheld Pulse Oximeter PalmSAT 2500A with Finger Clip Sensor [Paediatrics], Nonin Medical). Venous blood samples were also collected. The haemoglobin level of $<80 \mathrm{~g} / \mathrm{L}$ was classified as severe anaemia.

\section{Collection of patient information}

A standardised questionnaire was used to collect the sociodemographic and environmental data of households for children recruited only from February 2014 to March 2016. A Simple Poverty Scorecard for the Philippines, developed by Mark Schreiner, ${ }^{26}$ was used to assess the socioeconomic status (SES) of the household. This score uses 10 simple questions (the number of children per household; school attendance of the children; female head's education level; employment salary; material of the house's roof and walls; the type of toilet facility; and possession of a refrigerator, television or washing machine) and the scores ranged from 0 to 100 . Households with an SES score of $<30$ were defined as being in extreme poverty. A physical examination was conducted by a trained study physician, which included examination of neck rigidity, sensorial changes, grunting, decreased breath sounds, chest indrawing, rales, central cyanosis and nasal flaring. We considered the following signs as sensorial changes: irritability, drowsiness and stupor. The Glasgow Coma Scale was used for the assessment of coma and impaired consciousness. ${ }^{27}$ Glasgow Coma Scale of $<9$ was considered to indicate severe condition, while the scale of 9-12 was considered to indicate moderate condition.

\section{Assessment of chest X-ray}

Anteroposterior and lateral chest radiographs were obtained. The images were interpreted by a designated radiologist trained in the standard interpretation of chest radiographs for the diagnosis of childhood pneumonia, as developed by the WHO Pneumonia Vaccine Trial Investigators' Group. ${ }^{28}$ The chest X-ray findings in this study included end-point consolidation; other infiltrate and pleural effusion, and end-point pneumonia was defined as the presence of end-point consolidation or pleural effusion.

\section{Detection of viruses}

Nasopharyngeal swabs were obtained from patients and stored at $4^{\circ} \mathrm{C}$. The samples were shipped to RITM for processing and virus identification. Viral RNA and DNA were purified using the QIAamp MinElute Virus Spin Kit. Viral RNA was reverse transcribed to complementary DNA by the Moloney murine leukaemia virus reverse transcriptase with random hexamer primers. RSV, HMPV and PIV were detected in the samples by multiplex PCR using two methods. The first method involved detection of RSV and HMPV. The second method involved detection of PIV-1, PIV-2, PIV-3 and PIV-4. The RSV positive samples were further subtyped into RSV-A and RSV-B by performing nested PCR. ${ }^{29-32} \mathrm{RV}$ and enterovirus (EV) were detected from the clinical samples by targeting 5' non-coding region (NCR). The RV species (A, B, C) and serotypes of EV, including EV-D68, were further identified by sequencing and phylogenetic analysis of 5' NCR. RT-PCR was performed for the detection of IFV A(H1N1) pdm09, IFV A(H3N2) and IFV B. ${ }^{33}$ ADV detection was performed by combining viral isolation and neutralisation testing as well as PCR and serotyping by sequencing. ${ }^{34-36}$

\section{Detection of bacteria}

Blood drawing for bacterial culture identification was done only when informed consents were obtained from caregivers. One millilitre of venous blood sample was collected from each patient. The method for blood culture identification for bacteria is described elsewhere. ${ }^{14} \mathrm{We}$ considered the bacterial culture positive if at least one of the following 12 bacteria was identified: Acinetobacter baumannii, Burkholderia cepacia, Enterobacter aerogenes, $H$. influenzae, Klebsiella pneumoniae, Staphylococcus aureus, Pseudomonas aeruginosa, P. stutzeri, other Pseudomonas species, S. pneumoniae and Onchrobactrum anthropi. Virus-bacteria co-detection was defined positive for at least one virus and one pathogenic bacterium, while virus-virus co-detection was defined as patient with two or more viruses detected. Patients whose samples were negative for any of the target viruses and bacteria were considered negative for all pathogens.

\section{Data analysis}

The data were analysed based on two age groups: $<2$ months and 2-59 months, according to the IMCI guidelines. ${ }^{64}$ To investigate the aetiological and clinical factors associated with fatal outcomes, a generalised linear model was applied. This model was adjusted for the age of the patients, the year of sampling and the hospitals where the patients were admitted. A second model was also applied, wherein the association of death was evaluated in context of the clinical and radiological findings in six separate groups of children, including those positive for RSV, RV, $\mathrm{ADV}, \mathrm{EV}$, bacteria in blood and negative for any viruses. The second model was adjusted for the age of the patients, the year of sampling and the hospitals after matching with the age groups. The extent of association with the fatal outcome in both the models was evaluated by calculating the ORs and 95\% CI using a simple exact binomial calculation. Fisher exact test was applied to compare the frequencies, and Welch's t-test or Brunner-Munzel test was used to compare the means and medians of variables between the two groups. A $p$ value $<0.05$ indicated statistical significance. The comparison of case fatality rates (CFR) by the year of examination was performed using the Cochran-Armitage Test for Trend. Missing data were not included in the analysis. All statistical analyses were performed using the Microsoft R Open V.3.2.4 and Dplyr package. $^{37}$

\section{Patient involvement}

No patients were directly involved in the development of the research question, selection of the outcome measures, 
design and implementation of the study, or interpretation of the results.

\section{RESULTS}

From 2008 to 2016, 5128 children were enrolled in the study (online supplementary figure 1). Of these, the outcome data was available for $5054(98.6 \%)$ children; $74(1.4 \%)$ children were excluded from the analysis due to loss to follow-up, unknown outcome or transferred to another hospital. Out of the 5054 patients analysed, 749 $(14.8 \%)$ were aged $<2$ months and $4305(85.2 \%)$ were aged 2-59 months.

The CFR was slightly higher in patients aged $<2$ months than in those aged $2-59$ months $(5.3 \%$ vs $4.6 \%)$ and declined as the age of children increased (table 1). Children aged $<24$ months accounted for $87.0 \%$ of all fatal cases and the highest CFR (7\%) was observed in patients aged 2-5 months (table 1). Missing data of each parameter in table 1 are reported in online supplementary table 1.

There were more male patients $(n=2876,56.9 \%)$ than female patients $(n=2178,43.1 \%)$, although there was no significant association between the gender and outcome in both the age groups. A significant decreasing trend of CFR was observed during the 9-year study period, with the highest CFR of $12.5 \%$ recorded in 2008 and the lowest CFR of $2.0 \%$ recorded in $2013(\mathrm{p}<0.001)$ (online supplementary table 2). EVRMC showed the highest CFR among the hospitals in both the patient groups $(<2$ months, $7.8 \%$ and 2-59 months, $5.7 \%)$. CFRs were lower in BPH (3.2\%) and ONP $(2.1 \%)$. The presence of congenital abnormalities was significantly associated with the fatal outcome for both the age groups $(p<0.05)$. Severe underweight for age $(<-3 \mathrm{SD})$ was observed in $41.2 \%$ of the fatal cases in patients $<2$ months and in $39.2 \%$ of fatal cases in patients aged 2-59 months. The history of child loss in the family was significantly more frequent in fatal cases than in the survived group for children 2-59 months (33.3\% vs $10.2 \%, \mathrm{p}=0.003)$. Charcoal and wood were used as the cooking fuels by $86.5 \%$ of patient's families; however, no significant association was noted between the type of cooking fuels and outcomes.

Among the findings of physical examination, rales and chest indrawing were the most common signs in both the age groups (table 2). On admission, 19.1\% (968/5054) of fatal patients had fever $\left(>38.5^{\circ} \mathrm{C}\right)$, and the fever was significantly more frequent in the died group than in the survived group of both age groups. Sensorial changes were recorded in $28.0 \%$ of the fatal cases; these changes were significantly more frequent in the died group than in the survived group of both the age groups $(\mathrm{p}<0.001)$. Glasgow Coma Scale $<9$ was also significantly associated with fatal outcome in children aged 2-59 months $(\mathrm{p}<0.001)$. The prevalence rate of hypoxaemia was $13.0 \%$ (654/5023). Among the respiratory signs, grunting, decreased breath sounds, central cyanosis, apnoeic episode and $\mathrm{SpO}_{2}<90 \%$ were more commonly observed in the died group than in the survived group of both the age groups.

The proportion of patients with severe anaemia $(<80 \mathrm{~g} / \mathrm{L})$ was significantly higher in the died cases of both the age groups $(p<0.01)$, while the mean haemoglobin level was significantly lower only in the patients aged 2-59 months ( 100.3 vs $110.2 \mathrm{~g} / \mathrm{L} ; \mathrm{p}<0.001)$ (table 2 ). Missing data of each parameter in table 2 are reported in online supplementary table 3 .

A total of 4498 children had chest radiographs; of these, 4452 showed interpretable results. At least one abnormal finding was observed in 1711 (38.4\%) chest radiographs. Among the died cases, $41.6 \%$ patients showed end-point pneumonia, $5 \%$ had consolidation, 35\% had infiltrations and $3.4 \%$ had pleural effusion. These findings were significantly more common in the died cases than in the survived cases, except for pleural effusion in children aged $<2$ months.

Of the 5054 nasopharyngeal swabs, $61.0 \%$ tested positive for at least one virus. RSV was the most common viral pathogen, which was detected in 27.0\% (1352/5054), of which $135(10.0 \%)$ reported co-infection with other viruses. Rhinovirus was the second-most common viral pathogen, which was detected in $23.0 \%(1156 / 5054)$ of the cases, of which $173(17.6 \%)$ had dual co-infection infections with other viruses. The RSV positive rate was significantly lower in the died cases of the 2-59 months age group. A similar trend was also observed in patient group aged $<2$ months; however, the difference was not statistically significant. The positive rates of RSV-A, RSV-B and HMPV were also significantly lower in the died cases than in the survived cases among the patients aged 2-59 months. On the other hand, the positive rate of $\mathrm{ADV}$, specifically for ADV-7, was significantly higher in the died cases than in the survived cases for the patient aged 2-59 months, while the CFRs of ADV and ADV-7 were $10.7 \%$ and $24.0 \%$, respectively. The positive rate for EV-D68 was higher in the died cases than in the survived cases, although the difference was not statistically significant (table 3).

A total of 3018 blood samples were cultured for bacterial identification. The overall positivity rate for any pathogenic bacteria in the blood samples was 1.6\% (49/3018), and the CFR among the blood culture-positive cases was $18.3 \%(9 / 49)$. The most commonly identified bacterial pathogen was B. cepacia $(26.5 \%, \mathrm{n}=13)$, followed by S. pneumoniae $(22.4 \%, \mathrm{n}=11)$ and A. baumannii $(\mathrm{n}=5)$ (table 4). The positive rates for blood culture were significantly higher in the died cases than in the survived cases from both the age groups. Among the died cases from the patient group of 2-59 months, the identified bacteria included $P$. aeruginosa $(\mathrm{n}=2), S$. pneumoniae $(\mathrm{n}=2)$, methicillin-resistant Staphylococcus aureus $(\mathrm{n}=2)$, A. baumannii $(\mathrm{n}=1), B$. серасia $(\mathrm{n}=1)$ and $K$. pneumoniae $(\mathrm{n}=1)$, while $A$. baumannii and $K$. pneumoniae were identified in the died cases of age $<2$ months (table 3 ).

In the univariate analysis, the demographic, clinical and laboratory findings significantly associated with death 


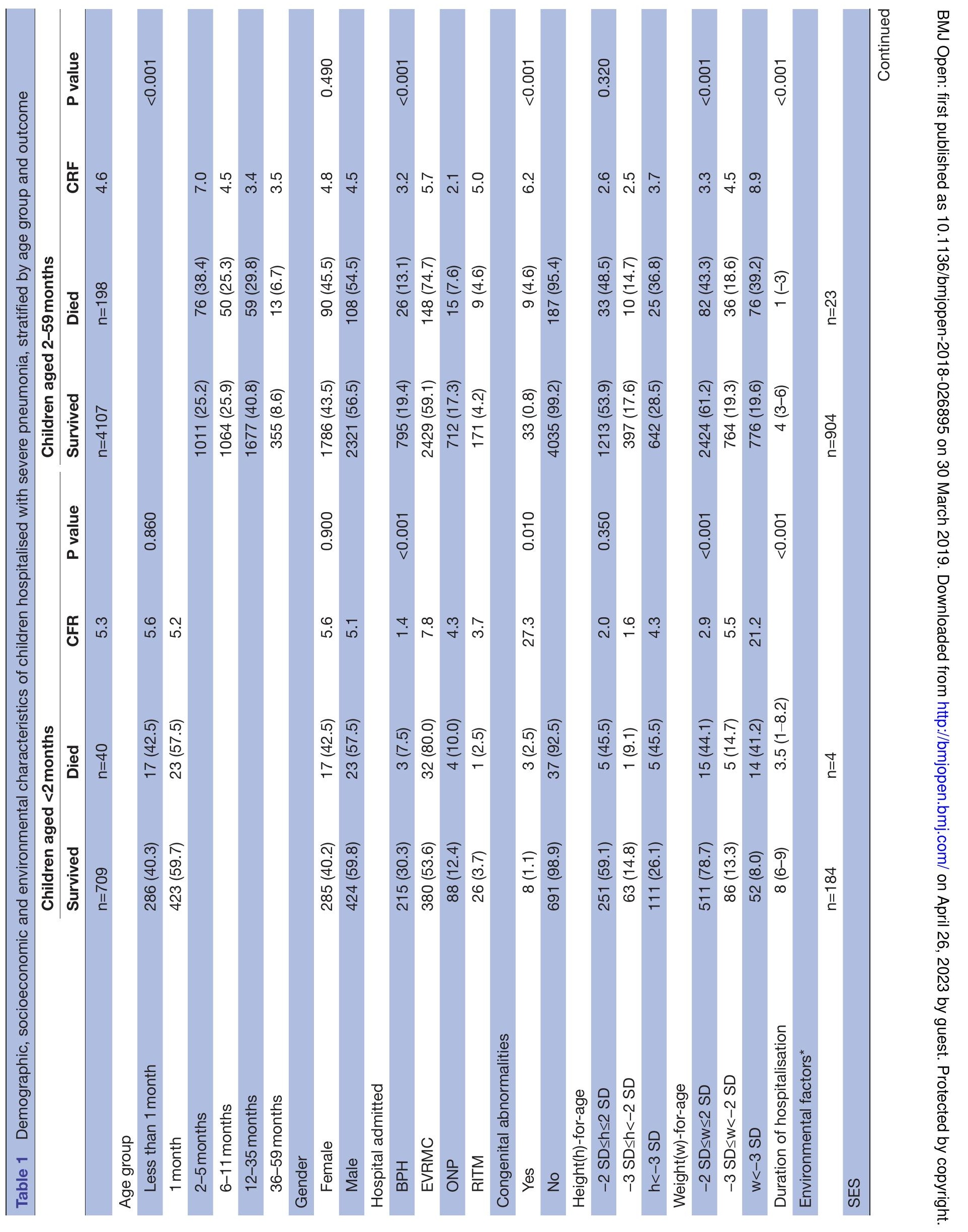




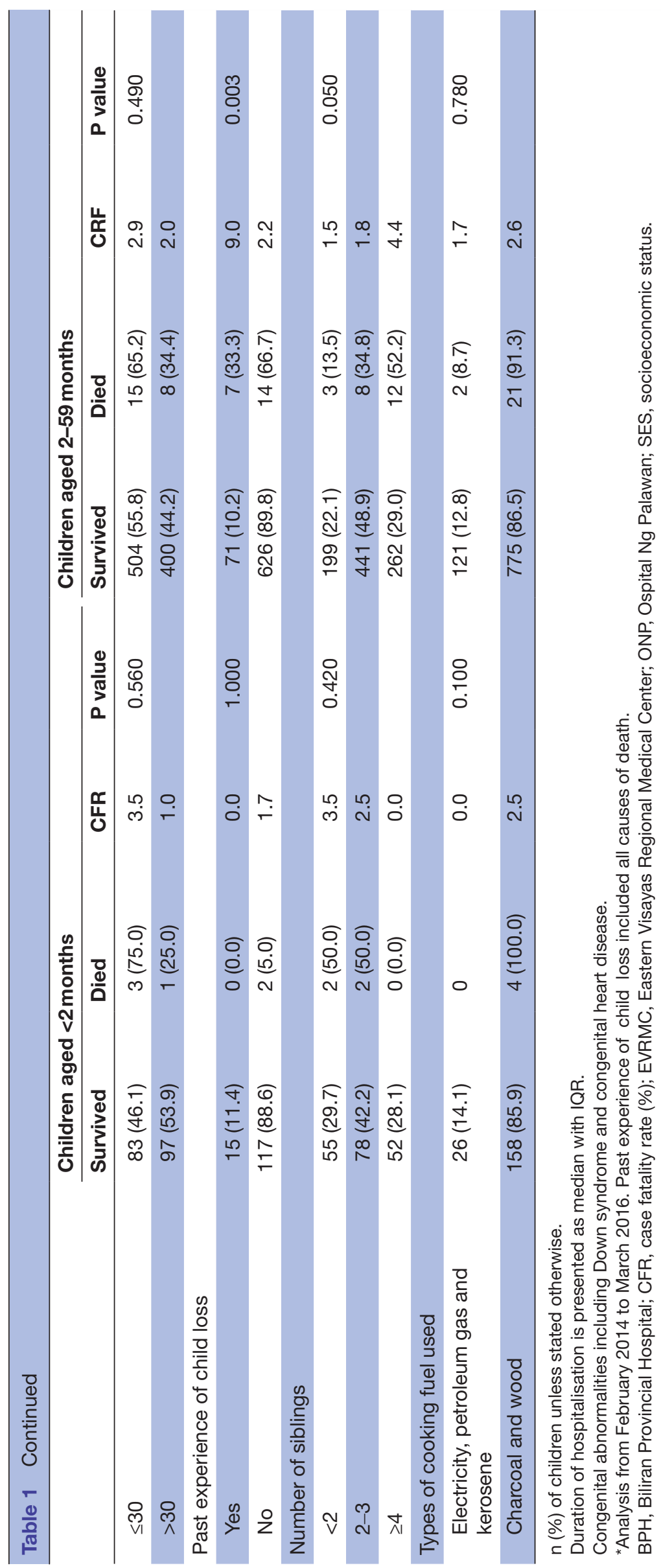




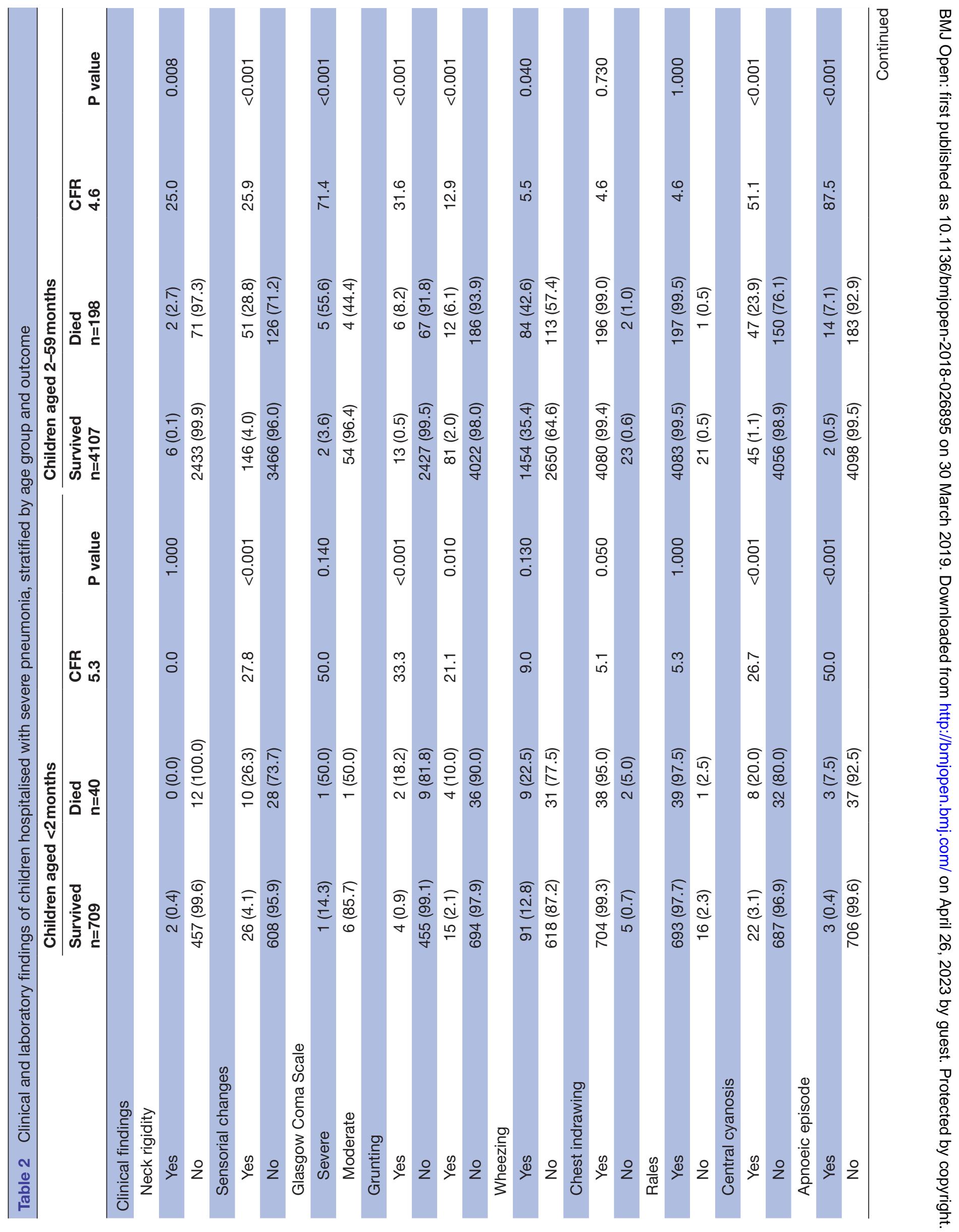




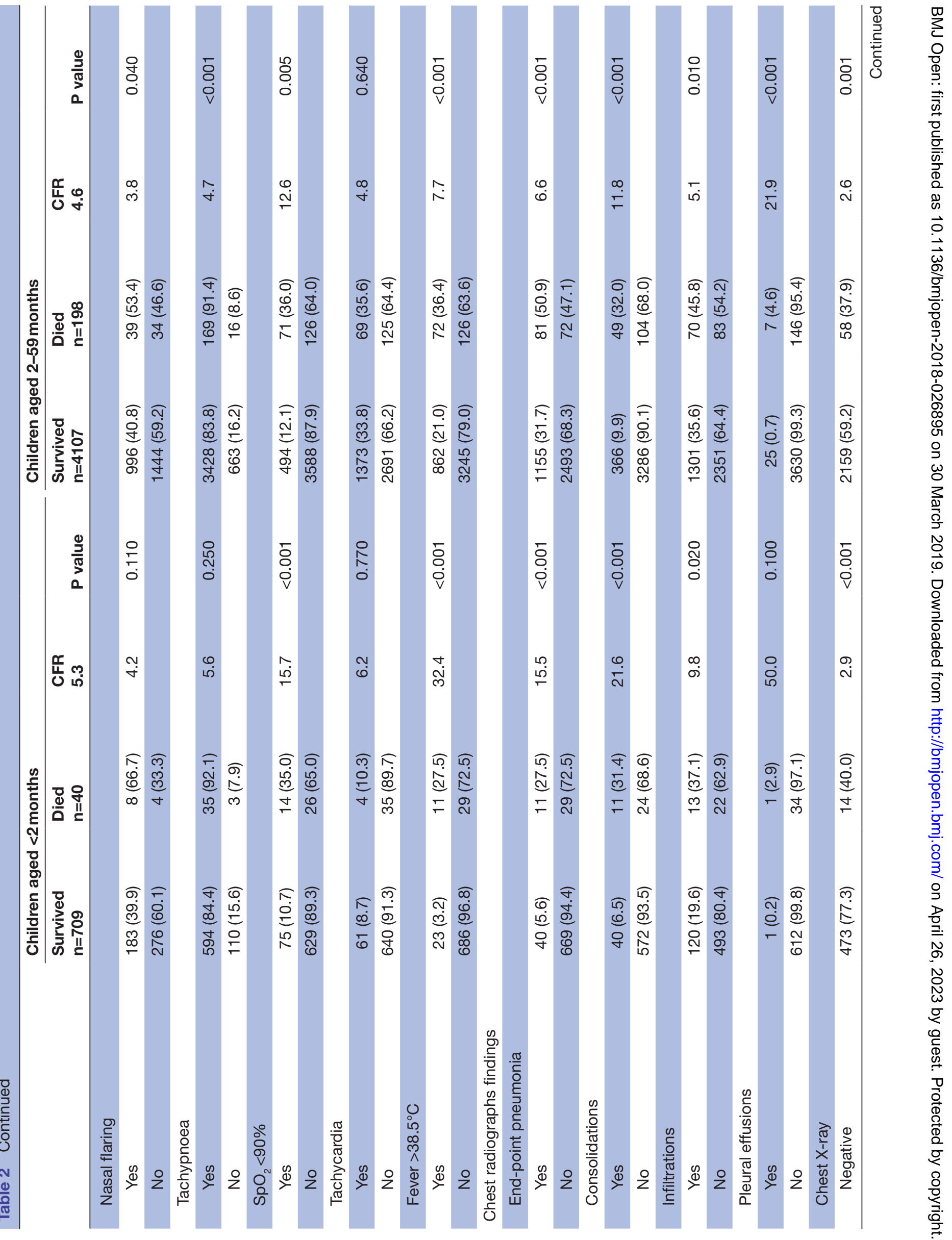




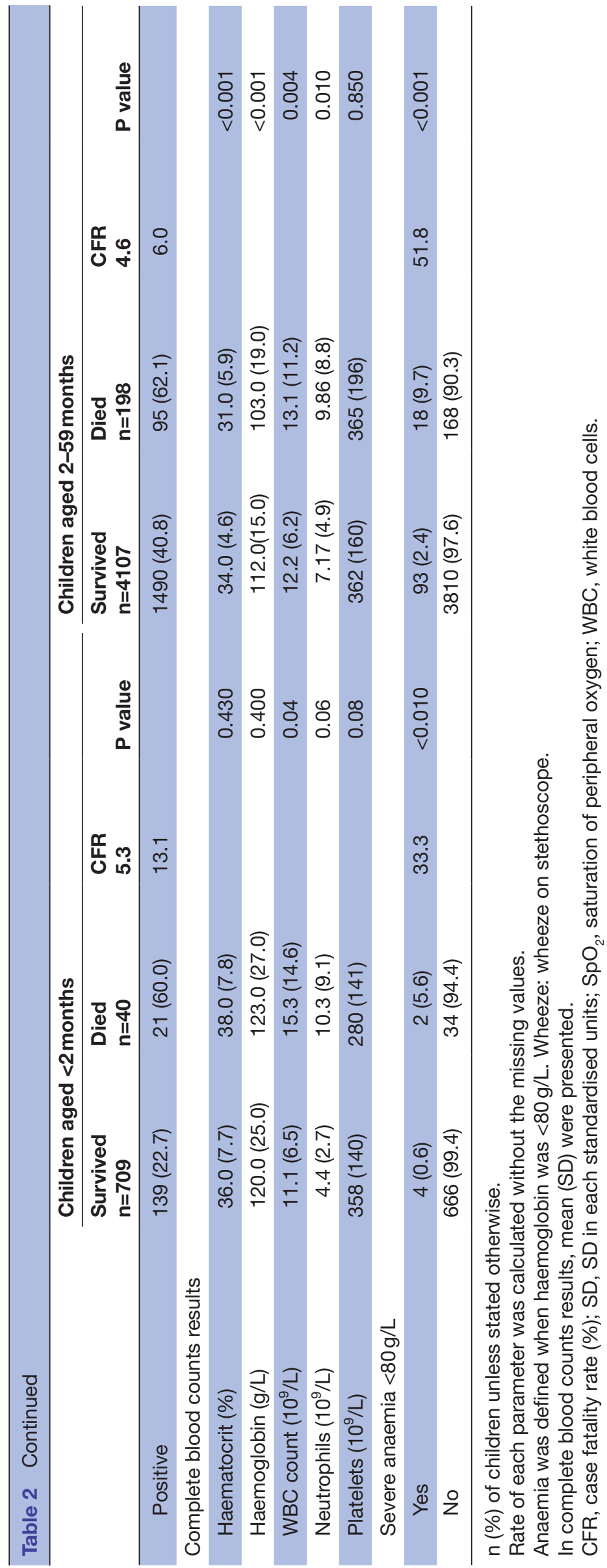




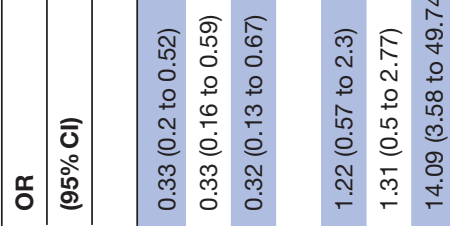

के

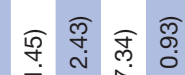

कृ

ก่ लु

군

ำ

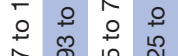

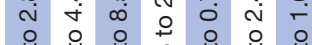

每

상

竞

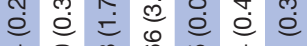

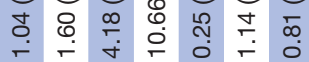

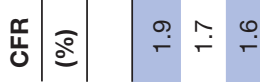

மூ

ஸீ:

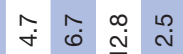

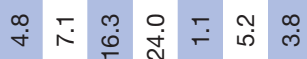

$\hat{\varphi}$

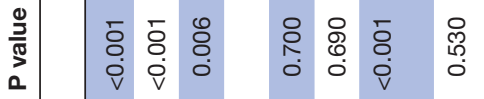

$\stackrel{\circ}{\circ}$

옹유융 융

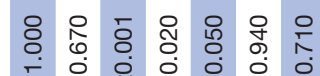

$\bar{\square}$

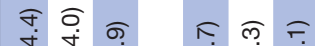
N

สูก

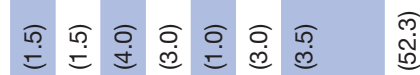
con

m ले $\frac{\infty}{0} \underbrace{}_{0}$

울

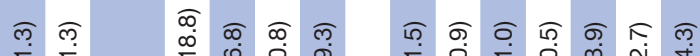
I

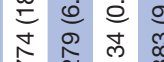

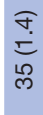

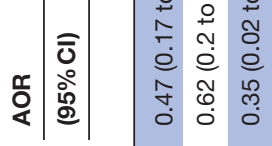

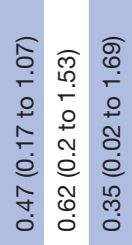

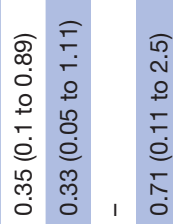

ส

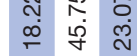

के

$\circ$ 의 웅요

is

荡

อ 巳

e 巳

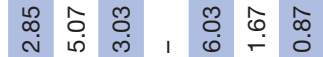

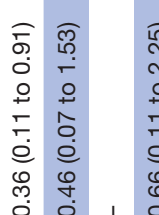

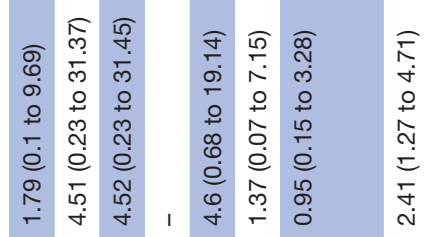

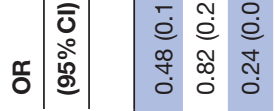

岳|

$\stackrel{\circ}{\circ} \stackrel{0}{0}$

웅웅

$\stackrel{m}{\sim} \hat{i} \stackrel{\circ}{\circ} \hat{\dot{m}}$

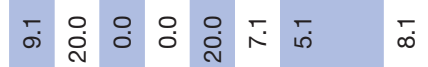

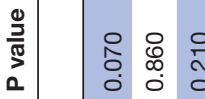

용 욷

웅

$\begin{array}{llll}0 & 0 \\ 0 & 0 & 0 & 0 \\ 0 & 0 & 0 \\ 0 & 0 & 0 \\ 0\end{array}$

竎 $\begin{aligned} & \text { 웡 } \\ & 0\end{aligned}$

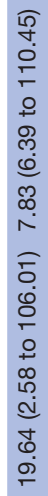

ำ

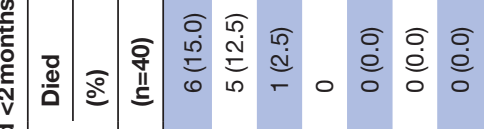

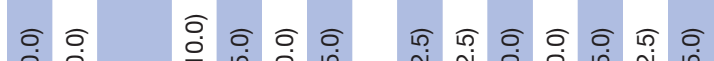

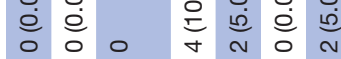

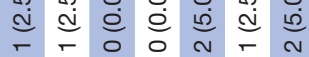

웅

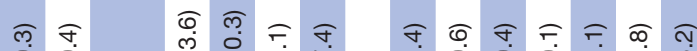

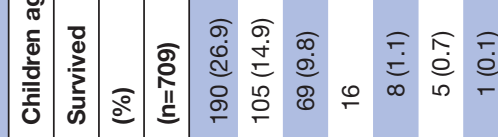

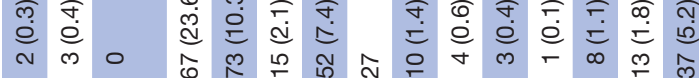

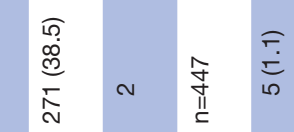


in both the age groups included severe underweight (weight-for-age $<-3 \mathrm{SD}$ ), presence of congenital abnormalities, decreased breath sounds, grunting, sensorial changes, central cyanosis, fever $\left(>38.5^{\circ} \mathrm{C}\right), \mathrm{SpO}_{2}<90 \%$, anaemia $(<80 \mathrm{~g} / \mathrm{L})$, endpoint pneumonia and blood culture positive for bacteria (tables 3 and 4). In addition, past experiences of child loss, tachypnoea and pleural effusion were associated with death in children aged 2-59 months. Infection with RSV (OR: 0.33 [95\% CI: 0.2 to 0.52 ]) and HMPV (OR: 0.25 [95\% CI: 0.04 to 0.79 ]) were negatively associated with death in patients aged 2-59 months (tables 3 and 4). In contrast, ADV (OR: 4.18 [95\% CI: 1.79 to 8.57]), particularly ADV-7 (OR: 10.66 [95\% CI: 3.68 to 27.77 ]) was positively associated with death in children aged 2-59 months.

After adjustment for age in months, year of sampling and hospital in the multivariate analysis, the following factors were found to be associated with death in both the age groups: severe underweight, presence of congenital abnormalities, decreased breath sounds, grunting, sensorial changes, central cyanosis, $\mathrm{SpO}_{2}(<90 \%)$, fever $\left(>38.5^{\circ} \mathrm{C}\right)$, anaemia $(<80 \mathrm{~g} / \mathrm{L})$, consolidation, infiltration, positive blood culture for bacteria (tables 3 and 4 ). Moreover, past experience of child loss, mild underweight (-3 SD $\leq \mathrm{w}<-2 \mathrm{SD})$, tachypnoea, tachycardia, ADV, ADV-7 and seasonal IFV $\mathrm{A}(\mathrm{H} 1 \mathrm{~N} 1)$ were found to be associated with death in children aged 2-59 months. In contrast, RSV, HMPV and RV-C infections showed decreased odds of death in children aged 2-59 months (tables 3 and 4).

We explored the factors associated with death for cases that were positive for RSV, RV, ADV, EV and blood culture for bacteria and negative for all viruses (table 5). The presence of fever $>38.5^{\circ} \mathrm{C}$ increased the odds of death in patients infected with RV, ADV, EV and bacteria and in patients who tested negative for viruses. The presence of hypoxaemia increased the odds of death in patients infected with RSV, RV and ADV. The presence of infiltration increased the odds of death in patients infected by RSV, ADV and EV. Interestingly, pleural effusion was associated with death in the group of patients who were tested negative to all viruses.

\section{DISCUSSION}

We recorded a significant decrease in the CFR among the patients hospitalised with severe pneumonia during the 9 -year study period. We also identified the risk factors associated with the deaths to be age of $2-5$ months, sensorial changes, severe malnutrition, grunting, central cyanosis, decreased breath sounds, tachypnoea, wheezing, fever $\left(\geq 38.5^{\circ} \mathrm{C}\right), \mathrm{SpO}_{2}<90 \%$, lung infiltration, consolidation and pleural effusion. Infection with ADV, seasonal influenza $A(H 1 N 1)$ and positive blood culture for bacteria were also found to be associated with mortality.

The overall CFR of children hospitalised with severe pneumonia in the present study was $4.7 \%$; this value is similar to that reported by other LMIC. ${ }^{18} 3839$ We also observed a significant decreasing trend of mortality 
Table 4 Factors associated with death among hospitalised children with severe pneumonia, stratified by age group

\begin{tabular}{|c|c|c|c|c|}
\hline \multirow[b]{2}{*}{ Factors } & \multicolumn{2}{|c|}{ Children aged $<2$ months } & \multicolumn{2}{|c|}{ Children aged 2-59 months } \\
\hline & $\begin{array}{l}\text { Crude OR } \\
(95 \% \mathrm{Cl})\end{array}$ & $\begin{array}{l}\text { Adjusted OR } \\
(95 \% \mathrm{Cl})\end{array}$ & $\begin{array}{l}\text { Crude OR } \\
(95 \% \mathrm{Cl})\end{array}$ & $\begin{array}{l}\text { Adjusted OR } \\
(95 \% \mathrm{Cl})\end{array}$ \\
\hline Less than 1 month & Ref. & Ref. & - & - \\
\hline 1 month & $0.93(0.6$ to 1.5$)$ & 0.9 (0.57 to 1.44$)$ & - & - \\
\hline $2-5$ months & - & - & 1.73 (1.17 to 2.69$)$ & 1.77 (1.19 to 2.75$)$ \\
\hline $12-35$ months & - & - & $0.97(0.72$ to 1.3$)$ & $0.96(0.72$ to 1.29$)$ \\
\hline $36-59$ months & - & - & Ref & Ref \\
\hline Past experience of child loss & NA & NA & 4.9 (1.83 to 11.87$)$ & $5.42(1.99$ to 13.51$)$ \\
\hline \multicolumn{5}{|l|}{ Weight(w)-for-age } \\
\hline Presence of congenital abnormalities & 7.0 (1.49 to 25.35$)$ & 1.96 (0.08 to 2.43$)$ & $5.88(2.62$ to 11.97$)$ & 3.12 (1.08 to 8.62$)$ \\
\hline Decreased breath sounds & 5.14 (1.41 to 15.03$)$ & 9.81 (2.11 to 46.49$)$ & $3.2(1.64$ to 5.76$)$ & 5.36 (2.6 to 10.38$)$ \\
\hline Grunting & 25.28 (3.22 to 148.64$)$ & 28.65 (2.89 to 259.6$)$ & $16.72(5.73$ to 43.71$)$ & 14.27 (4.64 to 39.86$)$ \\
\hline Sensorial changes & 1.59 (1.01 to 3.3$)$ & 1.79 (1.13 to 3.22$)$ & 9.61 (6.63 to 13.78$)$ & 8.31 (5.68 to 12.0$)$ \\
\hline Glasgow Coma Scale $<9$ & $6.0(0.15$ to 321.95$)$ & - & 45.0 (6.92 to 437.72$)$ & - \\
\hline Central cyanosis & 7.81 (3.07 to 18.33$)$ & $6.49(2.50$ to 15.63$)$ & 28.24 (18.19 to 43.95$)$ & 27.58 (17.55 to 43.5$)$ \\
\hline Tachypnoea & 1.20 (0.35 to 3.13$)$ & 2.03 (0.7 to 8.6$)$ & 2.04 (1.25 to 3.57$)$ & 1.89 (1.15 to 3.34$)$ \\
\hline Tachycardia & 2.16 (0.76 to 9.07$)$ & 2.03 (0.56 to 5.84$)$ & 1.08 (0.8 to 1.46$)$ & 2.09 (1.42 to 3.07$)$ \\
\hline $\mathrm{SpO}_{2}<90 \%$ & 4.52 (2.21 to 8.91$)$ & 4.69 (2.23 to 9.56) & 4.09 (3.0 to 5.54$)$ & 5.06 (3.67 to 6.94) \\
\hline
\end{tabular}

Multivariate logistic models were adjusted by age in month, year of sampling and hospitals.

$\mathrm{NA}$, not applicable; $\mathrm{SpO}_{2}$, saturation of peripheral oxygen

during the study period, which may be attributed to the improved access to healthcare facilities and the improved management of childhood pneumonia in the past decade. Another possible reason may be the introduction of new vaccines such as $H$. influenzae type b (Hib) vaccines and pneumococcal conjugate vaccines (PCV). These vaccines have been shown to reduce the mortality rate resulting from childhood pneumonia. ${ }^{78}$ However, in the Philippines, Hib vaccines were introduced in 2010, while PCVs were introduced in 2014 as part of the national immunisation programme of the country. ${ }^{40}$ Vaccination coverage for Hib and PCV were estimated at $67 \%$ and $35 \%$, respectively, in $2014 .^{40}$ Because a decreasing trend in CFR was observed before the introduction of these vaccines, other factors such as improved access to healthcare facilities and improved quality of care are more likely to have contributed to the CFR reduction.
Children aged $<24$ months accounted for $87.0 \%$ of total deaths, which is comparable with the global estimate of $81.0 \%$ pneumonia-related deaths occurring in children aged $<2$ years. ${ }^{41}$ Patients of age $2-5$ months showed the highest CFR of $7.0 \%$. Similar results have also been reported in a previous study conducted in the Philippines, wherein children of this age group were at risk for pneumonia-associated mortality. ${ }^{3}$ The immune system of patients in this age group is not fully functional, ${ }^{42}$ and children aged 2-5 months have a lower level of circulating IgG in the blood than in other age groups. ${ }^{43}$

Moreover, we noted an association between the history of child loss in the family among children aged $<2-59$ months, which may be due to the lack of financial resources in the family, limited access to healthcare facilities or inappropriate health-seeking behaviour of the caretakers, such as self-medication, which may result in 


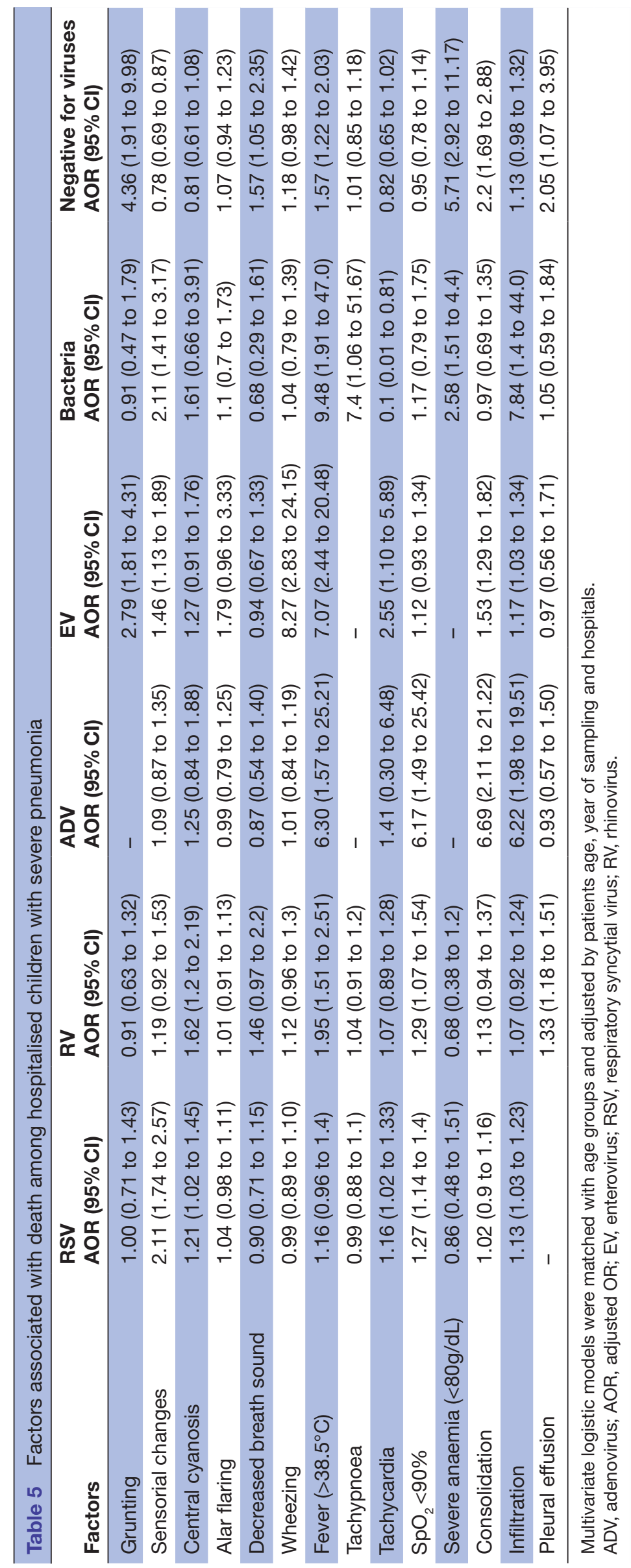


delayed commencement of proper care for children with pneumonia. ${ }^{44}$ The increased risk of pneumonia in households using solid cooking fuel and low SES has been well characterised in the past. ${ }^{26} 45-47$ However, we did not find any significant associations between these two factors and death. We collected the data on risk factors only from 2014. The scarcity of data and the homogeneous characteristic of patients from lower economic status may explain the lack of significant associations.

We observed that $55.0 \%$ of the patients who died were either moderately or severely underweight. A similar rate of $52.5 \%$ has been reported among undernourished patients who died of infectious diseases in LMIC among children aged $<5$ years. ${ }^{48}$ In a hospital-based study conducted in Malawi, the CFR attributed to pneumonia was high among patients with severe malnutrition, despite the general trend of decreasing CFR among patients with pneumonia, ${ }^{18}$ which suggest that severely malnourished children with pneumonia require intensive inpatient care. ${ }^{49}$ Guidelines for the management of pneumonia in malnourished children should consider this strong association with mortality.

Several clinical factors have been found to be associated with death, including decreased breath sounds, grunting, severe anaemia, central cyanosis and fever $\left(>38.5^{\circ} \mathrm{C}\right)$ which are consistent with those reported previously. ${ }^{18} 21$ In children aged $<2$ months, particular attention needs to be given to patients with fever $>38.5^{\circ} \mathrm{C}$, because of the high CFR of $32.5 \%$. A bacterial infection should be considered in pneumonia cases with fever $>38.5^{\circ} \mathrm{C}$, as reported elsewhere.$^{50}$ Wheeze was associated with death, contrasting with the finding from a previous study in which the presence of wheeze was protective against death. ${ }^{51}$ However, in our study, patients infected with EV, particularly EV-D68 showed high CFRs, and there was very strong association between wheezing and fatal outcome in patients with $\mathrm{EV}$ (table 5). EV-D68 is known to be more severe in children with asthma or recurrent wheeze. ${ }^{52}$ This may contribute to the overall association of wheeze with death.

The prevalence of hypoxaemia $\left(\mathrm{SpO}_{2}<90 \%\right)$ was $13.0 \%$ in this study, which is compatible to the mean rate of hypoxaemia among severe and very severe pneumonia cases reported in a review study. ${ }^{53}$ However, in the present study, some patients had received oxygen before $\mathrm{SpO}_{2}$ measurement, which may have underestimated the prevalence of hypoxia. Hypoxaemia was associated with death in our study, in concordance with earlier findings. ${ }^{22} 54-58$ In a multicentre study that included 5 LMIC, the CFR among the hypoxaemic patients was $8.5 \%,{ }^{59}$ which is lower than the range of CFRs $(12.6 \%-15.7 \%) \%)$ reported among hypoxaemic patients in this study. Hypoxaemia was associated with viral infections such as RV and RSV as well as with a poor outcome, particularly in ADV infection. ${ }^{60-64}$ In this study, hypoxaemia was significantly associated with death in patients infected with RV, RSV and ADV and in those with particularly high adjusted OR for ADV. Central cyanosis was also significantly associated with death for
RSV and RV which suggests that hypoxia is particularly important in viral infections (table 5).

In this study, the presence of a positive chest radiograph finding increased CFR. CFR among the consolidation cases was $13.0 \%$, which is the same as the reported mean CFR value of $13 \%$ in a multicentre study on childhood pneumonia. ${ }^{23}$ The positivity rates for abnormal findings of chest radiograph varied across countries with the type of population and the presence of comorbidities ${ }^{23}$ but the association of endpoint pneumonia and consolidation with death or treatment failure have been consistently reported. ${ }^{357} 58$ In addition, patients positive for RV and bacteria and negative for any viruses were more likely to die if they showed any abnormal findings by chest radiograph. These findings suggest that, among the patients positive for RV and negative for any viruses, a subset of the patients may have bacterial pneumonia.

Seasonal IFV A (H1N1) had a CFR of $40 \%$ in children aged 2-59 months, which was in contrast with the CRF value of $0 \%$ for IFV A (H1N1)pdm09. The reason why seasonal IFV A (H1N1) had such a high CFR remains unclear; however, it should be noted that all seasonal IFV $\mathrm{A}(\mathrm{H} 1 \mathrm{~N} 1)$ occurred during the period of 2008 to 2009, which was marked by an overall high CFR. ADV-7 had CFR of $24.0 \%$ in patients aged 2-59 months which concurs with a similar finding in China ${ }^{65}$ Most cases of ADV-7 in this study occurred between 2008 and 2011, which coincided with the ADV-7 outbreaks in Asia. ${ }^{656}$ CFR associated with EV-68 (8.5\%) was also higher than the average value. The association of EV-68 with severe ALRI, including pneumonia, has been well reported across several studies, including those reporting fatal cases. ${ }^{17} 67-69$ RSV was the most common virus identified in the present study, which agrees with some previous reports. ${ }^{14-16}$ However, RSV was negatively associated with death; this finding is also similar to those of several studies conducted in hospital settings. ${ }^{70-73} \mathrm{RV}$ presented with the highest number of deaths in this study. In contrast to RSV, which was significantly and inversely associated with death in children aged 2-59 months, RV did not have any positive or negative associations with deaths. $\mathrm{RV}$ is classified into three species: RV-A, B and C. CFRs for RV-A and B were higher than average, but the difference was not statistically significant. The CFR of RV-C was lower in patients aged 2-59 months, which was statistically significant in the univariate analysis. Some studies revealed that RV-C is associated with extremely severe respiratory infections, including deaths. ${ }^{74}$ However, our data does not support this association. As mentioned earlier, some RV-positive cases, especially those positive for RV-A and B, may include bacterial pneumonia cases. Further studies are required to define the true causal association of different RVs with pneumonia and deaths due to pneumonia. We also did not observe any increase in the risk of death among patients with multiple viral infections, which is consistent with an earlier report. ${ }^{75}$ However, the majority of multiple infections that occurred due to RV, RSV and both the viruses did not increase the risk of death. 
Blood culture positive for bacteria was associated with death, as reported elsewhere. ${ }^{76} 77$ However, the detection rate was low, which is similar to the findings of a few previously published reports, ${ }^{78} 79$ particularly with those conducted in the Philippines, which reported a positivity rate of $1.1 \% .^{80}$ The possibility of an antimicrobial treatment before admission in hospital may play a role in low positivity rate of blood culture. Although the sensitivity of blood culture for childhood pneumonia is extremely low, there are no alternative to the gold standard in the diagnosis of bacterial pneumonia in children. The difficulty in obtaining proper sputum samples from children also prevented us from identifying the pathogens in patients. ${ }^{81}$

This study has some limitations. First, the inclusion of the DAMA-deteriorated cases as deaths could have increased the CFR value. Second, we started collecting information on the risk factors from 2014 onward. Third, some clinical and laboratory data were missing, especially in fatal cases, because several deaths occurred immediately after hospital admission. Similarly, the sampling rate for blood culture was lower for fatal cases, because the patients died before their samples could be obtained. Despite these limitations, our study had a large sample size of more than 5000 patients studied over a longer duration of 9 years in a lower-middle-income country, which allowed us to accumulate comprehensive data on the demographics, clinical characteristics and aetiology of hospitalised children with severe pneumonia.

\section{CONCLUSION}

Our study demonstrated that while the CFR showed a decreasing trend in the past 10 years, severe pneumonia remains a major cause of morbidity and mortality in hospitalised infants and young children. We identified several factors that are associated with mortality, including severe malnutrition, fever $>38.5^{\circ} \mathrm{C}$, lung infiltration and consolidation on chest radiograph, $\mathrm{SpO}_{2}<90 \%$ and respiratory distress syndrome such as central cyanosis, tachypnoea and wheezing. Infection with ADV-7 and seasonal influenza A (H1N1) and positive blood culture for bacteria have been associated with mortality, while infection with RSV and RV was negatively associated with mortality.

\section{Author affiliations}

${ }^{1}$ Virology, Tohoku University Graduate School of Medicine, Sendai, Miyagi, Japan

${ }^{2}$ Research Institute for Tropical Medicine, Muntinlupa City, Philippines

${ }^{3}$ Division of International Cooperation for Disaster Medicine, International Research Institute of Disaster Science, Tohoku University, Sendai, Japan

Acknowledgements We acknowledge the patients and caregivers for their participation in this study. We acknowledge all health officers, medical doctors, nurses, laboratory technicians who were involved in this study in all four hospitals in the Philippines (BPH, EVRMC, ONP and RITM) and all technicians, students and medical scientists who were involved in this study in Tohoku University Graduate School of Medicine.

Contributors Conceived and designed the study: HO, SL. Collected clinical data and samples: RT, SL, VT, MS, MS. Performed laboratory diagnosis of pathogens: MO, ESM, MM, MAUI. Analysed the data: BPPD, TK, CD, HO. Drafted the manuscript: $B P P D, T K, C D, E S, H O$. Critically reviewed and approved the manuscript: all authors.
Funding This work was supported by the Japan Initiative for Global Research Network on Infectious Diseases from the Japan Agency for Medical Research and Development (AMED) [grant number JP18fm108013]; the Science and Technology Research Partnership for Sustainable Development from AMED and Japan International Cooperation Agency [grant number JP16jm0110001].

Competing interests None declared.

Patient consent for publication Obtained.

Ethics approval The study protocol was approved by the Ethics Committee of Tohoku University Graduate School of Medicine and the Institutional Review Board of RITM.

Provenance and peer review Not commissioned; externally peer reviewed.

Data sharing statement № additional data are available, all available data have been disclosed.

Open access This is an open access article distributed in accordance with the Creative Commons Attribution Non Commercial (CC BY-NC 4.0) license, which permits others to distribute, remix, adapt, build upon this work non-commercially, and license their derivative works on different terms, provided the original work is properly cited, appropriate credit is given, any changes made indicated, and the use is non-commercial. See: http://creativecommons.org/licenses/by-nc/4.0/.

\section{REFERENCES}

1. UNICEF. Levels \& Trends in Child Mortality Report 2017 Estimates Developed by theUN Inter-agency Group for Child Mortality Estimation. United Nations Children's Fund, 2017.

2. Walker CL, Rudan I, Liu L, et al. Global burden of childhood pneumonia and diarrhoea. Lancet 2013;381:1405-16.

3. Lupisan SP, Ruutu P, Erma Abucejo-Ladesma P, et al. Predictors of death from severe pneumonia among children 2-59 months old hospitalized in Bohol, Philippines: implications for referral criteria at a first-level health facility. Trop Med Int Health 2007;12:962-71.

4. Johnson AW, Osinusi K, Aderele Wl, et al. Etiologic agents and outcome determinants of community-acquired pneumonia in urban children: a hospital-based study. J Natl Med Assoc 2008;100:370-85.

5. Enarson PM, Gie R, Enarson DA, et al. Development and implementation of a national programme for the management of severe and very severe pneumonia in children in Malawi. PLoS Med 2009;6:e1000137.

6. WHO. Handbook: IMCl integrated management of childhood illness: World Health Organization, 2005:173.

7. Becker-Dreps S, Amaya E, Liu L, et al. Changes in childhood pneumonia and infant mortality rates following introduction of the 13 -valent pneumococcal conjugate vaccine in Nicaragua. Pediatr Infect Dis J 2014;33:637-42.

8. Theodoratou E, Johnson S, Jhass A, et al. The effect of Haemophilus influenzae type $b$ and pneumococcal conjugate vaccines on childhood pneumonia incidence, severe morbidity and mortality. Int $J$ Epidemiol 2010;39(Suppl 1):i172-85.

9. Black RE, Cousens S, Johnson HL, et al. Global, regional, and national causes of child mortality in 2008: a systematic analysis. Lancet 2010;375:1969-87.

10. García Gabarrot G, López Vega M, Pérez Giffoni G, et al. Effect of pneumococcal conjugate vaccination in Uruguay, a middle-income country. PLoS One 2014;9:e112337.

11. Ruuskanen O, Lahti E, Jennings LC, et al. Viral pneumonia. Lancet 2011;377:1264-75.

12. Shi T, McAllister DA, O'Brien KL, et al. Global, regional, and national disease burden estimates of acute lower respiratory infections due to respiratory syncytial virus in young children in 2015: a systematic review and modelling study. Lancet 2017;390:946-58.

13. Nair $\mathrm{H}$, Brooks WA, Katz M, et al. Global burden of respiratory infections due to seasonal influenza in young children: a systematic review and meta-analysis. Lancet 2011;378:1917-30.

14. Suzuki $A$, Lupisan $S$, Furuse $Y$, et al. Respiratory viruses from hospitalized children with severe pneumonia in the Philippines. BMC Infect Dis 2012;12:267.

15. Jain S, Williams DJ, Arnold SR, et al. Community-acquired pneumonia requiring hospitalization among U.S. children. $N$ Engl J Med 2015;372:835-45.

16. García-García ML, Calvo C, Pozo F, et al. Spectrum of respiratory viruses in children with community-acquired pneumonia. Pediatr Infect Dis J 2012;31:808-13. 
17. Martin G, Li R, Cook VE, et al. Respiratory Presentation of Pediatric Patients in the 2014 Enterovirus D68 Outbreak. Can Respir J 2016;2016:8302179.

18. Lazzerini M, Seward N, Lufesi N, et al. Mortality and its risk factors in Malawian children admitted to hospital with clinical pneumonia, 2001-12: a retrospective observational study. Lancet Glob Health 2016;4:e57-68.

19. Sonego M, Pellegrin MC, Becker G, et al. Risk factors for mortality from acute lower respiratory infections (ALRI) in children under five years of age in low and middle-income countries: a systematic review and meta-analysis of observational studies. PLoS One 2015; 10:e0116380.

20. Barton L, Hodgman JE, Pavlova Z. Causes of death in the extremely low birth weight infant. Pediatrics 1999;103:446-51.

21. Spooner V, Barker J, Tulloch S, et al. Clinical signs and risk factors associated with pneumonia in children admitted to Goroka Hospital, Papua New Guinea. J Trop Pediatr 1989;35:295-300.

22. Lazzerini M, Sonego M, Pellegrin MC. Hypoxaemia as a Mortality Risk Factor in Acute Lower Respiratory Infections in Children in Low and Middle-Income Countries: Systematic Review and MetaAnalysis. PLoS One 2015;10:e0136166.

23. Fancourt N, Deloria Knoll M, Baggett HC, et al. Chest Radiograph Findings in Childhood Pneumonia Cases From the Multisite PERCH Study. Clin Infect Dis 2017:64:S262-S70.

24. WHO. Revised WHO classification and treatment of childhood pneumonia at health facilities: evidence summaries. World Health Organization 2014.

25. Cole TJ, Green PJ. Smoothing reference centile curves: the LMS method and penalized likelihood. Stat Med 1992;11:1305-19.

26. Kosai H, Tamaki R, Saito M, et al. Incidence and Risk Factors of Childhood Pneumonia-Like Episodes in Biliran Island, Philippines--A Community-Based Study. PLoS One 2015;10:e0125009.

27. Jennett B, Teasdale G. Aspects of coma after severe head injury. Lancet 1977:1:878-81.

28. WHO. Standardization of interpretation of chest radiographs for the diagnosis of pneumonia in children: World Health Organization, 2001.

29. Bonroy C, Vankeerberghen A, Boel A, et al. Use of a multiplex real-time PCR to study the incidence of human metapneumovirus and human respiratory syncytial virus infections during two winter seasons in a Belgian paediatric hospital. Clin Microbiol Infect 2007:13:504-9.

30. Matsuzaki Y, Mizuta K, Takashita E, et al. Comparison of virus isolation using the Vero E6 cell line with real-time RT-PCR assay for the detection of human metapneumovirus. BMC Infect Dis 2010;10:170

31. Bellau-Pujol S, Vabret A, Legrand L, et al. Development of three multiplex RT-PCR assays for the detection of 12 respiratory RNA viruses. J Virol Methods 2005;126:53-63.

32. Ohno A, Suzuki A, Lupisan S, et al. Genetic characterization of human respiratory syncytial virus detected in hospitalized children in the Philippines from 2008 to 2012. J Clin Virol 2013;57:59-65.

33. NIID. Influenza diagnosis manual. National Institute of Infectious Diseases. 2014:36-45 https://www.niid.go.jp/niid/images/labmanual/Influenza2014.pdf (accessed 05 Aug 2018).

34. Yamamoto D, Okamoto M, Lupisan S, et al. Impact of human adenovirus serotype 7 in hospitalized children with severe fatal pneumonia in the Philippines. Jpn J Infect Dis 2014;67:105-10.

35. Heim A, Ebnet $\mathrm{C}$, Harste $\mathrm{G}$, et al. Rapid and quantitative detection of human adenovirus DNA by real-time PCR. J Med Virol 2003;70:228-39.

36. Casas I, Avellon A, Mosquera M, et al. Molecular identification of adenoviruses in clinical samples by analyzing a partial hexon genomic region. J Clin Microbiol 2005;43:6176-82.

37. Wickham $\mathrm{H}$, François $\mathrm{R}$, Henry L, et al. A grammar of data manipulation, 2018.

38. Ayieko P, Okiro EA, Edwards T, et al. Variations in mortality in children admitted with pneumonia to Kenyan hospitals. PLOS One 2012; 7:e47622.

39. Naheed A, Saha SK, Breiman RF, et al. Multihospital surveillance of pneumonia burden among children aged $<5$ years hospitalized for pneumonia in Bangladesh. Clin Infect Dis 2009;48(Suppl 2):S82-9.

40. WHO. Immunization, vaccines and biologicals. http://www.who.int/ immunization/monitoring_surveillance/data/en/ (accessed 03 Sep 2018)

41. Walker CLF, Rudan I, Liu L, et al. Global burden of childhood pneumonia and diarrhoea. Lancet 2013;381:1405-16.

42. Simon AK, Hollander GA, McMichael A. Evolution of the immune system in humans from infancy to old age. Proc Biol Sci 2015;282:20143085
43. Agarwal S, Cunningham-Rundles C. Assessment and clinical interpretation of reduced IgG values. Ann Allergy Asthma Immunol 2007;99:281-3

44. Kim SA, Capeding MR, Kilgore PE. Factors influencing healthcare utilization among children with pneumonia in Muntinlupa City, the Philippines. Southeast Asian J Trop Med Public Health 2014;45:727-35

45. Fonseca Lima EJ, Mello MJ, Albuquerque MF, et al. Risk factors for community-acquired pneumonia in children under five years of age in the post-pneumococcal conjugate vaccine era in Brazil: a case control study. BMC Pediatr 2016;16:157.

46. Mahalanabis D, Gupta S, Paul D, et al. Risk factors for pneumonia in infants and young children and the role of solid fuel for cooking: a case-control study. Epidemiol Infect 2002;129:65-71.

47. Ezeh OK, Agho KE, Dibley MJ, et al. The effect of solid fuel use on childhood mortality in Nigeria: evidence from the 2013 crosssectional household survey. Environ Health 2014;13:113.

48. Caulfield LE, de Onis M, Blössner M, et al. Undernutrition as an underlying cause of child deaths associated with diarrhea, pneumonia, malaria, and measles. Am J Clin Nutr 2004:80:193-8.

49. Agweyu A, Lilford RJ, English M, et al. Appropriateness of clinical severity classification of new WHO childhood pneumonia guidance: a multi-hospital, retrospective, cohort study. Lancet Glob Health 2018;6:e74-e83.

50. Michelow IC, Olsen K, Lozano J, et al. Epidemiology and clinical characteristics of community-acquired pneumonia in hospitalized children. Pediatrics 2004;113:701-7.

51. Hooli S, Colbourn T, Lufesi N, et al. Correction: Predicting Hospitalised Paediatric Pneumonia Mortality Risk: An External Validation of RISC and mRISC, and Local Tool Development (RISCMalawi) from Malawi. PLoS One 2018:13:e0193557.

52. Schuster JE, Miller JO, Selvarangan R, et al. Severe enterovirus 68 respiratory illness in children requiring intensive care management. $J$ Clin Virol 2015;70:77-82

53. Subhi R, Adamson M, Campbell $\mathrm{H}$, et al. The prevalence of hypoxaemia among ill children in developing countries: a systematic review. Lancet Infect Dis 2009;9:219-27.

54. Duke T, Mgone J, Frank D. Hypoxaemia in children with severe pneumonia in Papua New Guinea. Int $J$ Tuberc Lung Dis 2001;5:511-9.

55. Onyango FE, Steinhoff MC, Wafula EM, et al. Hypoxaemia in young Kenyan children with acute lower respiratory infection. BMJ 1993;306:612-5.

56. Asghar R, Banajeh S, Egas J, et al. Chloramphenicol versus ampicillin plus gentamicin for community acquired very severe pneumonia among children aged 2-59 months in low resource settings: multicentre randomised controlled trial (SPEAR study). BMJ 2008;336:80-4

57. Kelly MS, Crotty EJ, Rattan MS, et al. Chest Radiographic Findings and Outcomes of Pneumonia Among Children in Botswana. Pediatr Infect Dis J 2016;35:257-62.

58. Basnet S, Sharma A, Mathisen M, et al. Predictors of duration and treatment failure of severe pneumonia in hospitalized young Nepalese children. PLoS One 2015;10:e0122052.

59. Bénet T, Picot VS, Awasthi S, et al. Severity of Pneumonia in Under 5-Year-Old Children from Developing Countries: A Multicenter, Prospective, Observational Study. Am J Trop Med Hyg 2017;97:68-76

60. Peled N, Nakar C, Huberman H, et al. Adenovirus infection in hospitalized immunocompetent children. Clin Pediatr 2004;43:223-9.

61. Wu PQ, Li X, Jiang WH, et al. Hypoxemia is an independent predictor of bronchiolitis obliterans following respiratory adenoviral infection in children. Springerplus 2016;5:1622.

62. Ghanaiem H, Averbuch D, Koplewitz BZ, et al. An outbreak of adenovirus type 7 in a residential facility for severely disabled children. Pediatr Infect Dis J 2011;30:948-52.

63. Tran DN, Trinh QD, Pham NT, et al. Clinical and epidemiological characteristics of acute respiratory virus infections in Vietnamese children. Epidemiol Infect 2016;144:527-36.

64. Riccetto AG, Ribeiro JD, Silva MT, et al. Respiratory syncytial virus (RSV) in infants hospitalized for acute lower respiratory tract disease: incidence and associated risks. Braz J Infect Dis 2006:10:357-61.

65. Yu Z, Zeng Z, Zhang J, et al. Fatal Community-acquired Pneumonia in Children Caused by Re-emergent Human Adenovirus 7d Associated with Higher Severity of IIIness and Fatality Rate. Sci Rep 2016;6:37216.

66. Shen CF, Wang SM, Ho TS, Ts H, et al. Clinical features of community acquired adenovirus pneumonia during the 2011 community outbreak in Southern Taiwan: role of host immune response. BMC Infect Dis 2017:17:196. 
67. Rao S, Messacar K, Torok MR, et al. Enterovirus D68 in Critically III Children: A Comparison With Pandemic H1N1 Influenza. Pediatr Crit Care Med 2016;17:1023-31.

68. Midgley CM, Watson JT, Nix WA, et al. Severe respiratory illness associated with a nationwide outbreak of enterovirus D68 in the USA (2014): a descriptive epidemiological investigation. Lancet Respir Med 2015;3:879-87.

69. Imamura T, Oshitani $\mathrm{H}$. Global reemergence of enterovirus D68 as an important pathogen for acute respiratory infections. Rev Med Virol 2015;25:102-14.

70. Kelly MS, Smieja M, Luinstra K, et al. Association of respiratory viruses with outcomes of severe childhood pneumonia in Botswana. PLoS One 2015:10:e0126593.

71. Szabo SM, Gooch KL, Bibby MM, et al. The risk of mortality among young children hospitalized for severe respiratory syncytial virus infection. Paediatr Respir Rev 2013;13 Suppl 2(Suppl 2):S1-8.

72. Welliver RC, Checchia PA, Bauman $\mathrm{JH}$, et al. Fatality rates in published reports of RSV hospitalizations among high-risk and otherwise healthy children. Curr Med Res Opin 2010;26:2175-81.

73. Oladokun R, Muloiwa R, Hsiao NY, et al. Clinical characterisation and phylogeny of respiratory syncytial virus infection in hospitalised children at Red Cross War Memorial Children's Hospital, Cape Town. BMC Infect Dis 2016;16:236.
74. Kiang D, Yagi S, Kantardjieff KA, et al. Molecular characterization of a variant rhinovirus from an outbreak associated with uncommonly high mortality. J Clin Virol 2007;38:227-37.

75. Cebey-López M, Herberg J, Pardo-Seco J, et al. Does Viral CoInfection Influence the Severity of Acute Respiratory Infection in Children? PLoS One 2016;11:e0152481.

76. McMullan BJ, Bowen A, Blyth CC, et al. Epidemiology and Mortality of Staphylococcus aureus Bacteremia in Australian and New Zealand Children. JAMA Pediatr 2016;170:979-86.

77. McGowan JE, Bratton L, Klein JO, et al. Bacteremia in febrile children seen in a "walk-in" pediatric clinic. N Engl J Med 1973;288:1309-12.

78. Murdoch DR, O'Brien KL, Driscoll AJ, et al. Laboratory methods for determining pneumonia etiology in children. Clin Infect Dis 2012;54(Suppl 2):S146-52.

79. Shah SS, Dugan MH, Bell LM, et al. Blood cultures in the emergency department evaluation of childhood pneumonia. Pediatr Infect Dis $J$ 2011;30:475-9.

80. Puumalainen T, Quiambao B, Abucejo-Ladesma E, et al. Clinical case review: a method to improve identification of true clinical and radiographic pneumonia in children meeting the World Health Organization definition for pneumonia. BMC Infect Dis 2008;8:95

81. Rodrigues CMC, Groves H. Community-Acquired Pneumonia in Children: the Challenges of Microbiological Diagnosis. J Clin Microbiol 2018;56:56. 